\title{
Costs, outcomes and challenges for diabetes care in Spain
}

\author{
Julio Lopez-Bastida ${ }^{1,2^{*}}$, Mauro Boronat ${ }^{3}$, Juan Oliva Moreno ${ }^{2,4}$ and Willemien Schurer ${ }^{5}$
}

\begin{abstract}
Background: Diabetes is becoming of increasing concern in Spain due to rising incidence and prevalence, although little information is known with regards to costs and outcomes. The information on cost of diabetes in Spain is fragmented and outdated. Our objective is to update diabetes costs, and to identify outcomes and quality of care of diabetes in Spain.

Methods: We performed systematic searches from secondary sources, including scientific literature and government data and reports.

Results: Diabetes Type II prevalence is estimated at 7.8\%, and an additional $6 \%$ of the population is estimated to be undiagnosed. Four Spanish diabetes cost studies were analyzed to create a projection of direct costs in the NHS and productivity losses, estimating $€ 5.1$ billion for direct costs along with $€ 1.5$ billion for diabetes-related complications (2009) and labour productivity losses represented $€ 2.8$ billion. Glycemic control (glycolysated hemoglobin) is considered acceptable in 59\% of adult Type II cases, in addition to $85 \%$ with HDL cholesterol $\geq 40 \mathrm{mg} / \mathrm{dl}$ and $65 \%$ with blood pressure $<140 / 90 \mathrm{mmHg}$, pointing to good intermediate outcomes. However, annual figures indicate that over half of the Type II diabetics are obese (BMI >30), 15\% have diabetic retinopathy, $16 \%$ with microalbuminuria, and $15 \%$ with cardiovascular disease.
\end{abstract}

Conclusions: The direct health care costs ( $8 \%$ of the total National Health System expenditure) and the loss of labour productivity are high. The importance of a multi-sectoral approach in prevention and improvements in management of diabetes are discussed, along with policy considerations to help modify the disease course.

Keywords: Diabetes, Costs, Outcomes, Quality of care, Prevalence, Incidence, Spain

\section{Background}

Diabetes mellitus (DM) is a leading health problem globally. DM is one of the leading causes of mortality and major morbidities, including cardiovascular disease (CVD), kidney failure, amputations and blindness [1]. The risk of developing these conditions is higher for diabetic patients compared with non-diabetic patients in the same age-group $[2,3]$.

A longitudinal chronic disease study found that diabetes incidence increased with age, with almost $20 \%$ prevalence in people aged over 65 years, and half all diabetic patients are aged over 65 years. By 2050, diabetes cases are

\footnotetext{
* Correspondence: julio.lopezbastida@uclm.es

'University Castilla La Mancha, Avda Real Fábrica de Seda s/n, Talavera de la Reina, Toledo 45600, Spain

${ }^{2}$ Red de Investigación en Servicios Sanitarios en Enfermedades Crónicas (REDISSEC), Spain

Full list of author information is available at the end of the article
}

projected to increase four-fold in patients older than 70 years [4]. It requires a continuous lifetime medical model to slow down the development of complications, improve quality of life and minimize its high social costs. The development of diabetes-related complications depends on glycemic control, but also on cardiovascular risk factors such as obesity, poor diet and inactivity. Multidisciplinary health care, along with high patient involvement, is integral to good diabetes management.

In Spain, diabetes exerts a great impact on public health due to its high prevalence (6.2\% aged 30-65 years; $10 \%$ aged $30-89$ years) $[5,6]$, but also for its acute and chronic complications and high mortality rate. Diabetes Type I prevalence is $0.2-0.3 \%$, while annual incidence under 14 years of age is 9.5-16/100,000 inhabitants annually; and in 15 to 29 years of age is $9.9 /$ 100,000 inhabitants annually. In children under 5 years,

\section{Biomed Central}


incidence is minimal. There was no discernible difference in diabetes incidence between the sexes until after the age of 15, when Type I incidence was found to be greater in males [7-10]. The estimated incidence of both Type I and II diabetes is $11-12 / 100,000$ and $8 / 1000$ inhabitants annually, respectively $[5,6]$. Sole Type II diabetes incidence data is scarce due to insufficient data [11], however, it is accepted that both incidence and prevalence are increasing in Type II with decreasing age at diagnosis.

A national Spanish study based on 5,800 surveys examined diabetes prevalence, obesity and associated risk factors, and found that Type II prevalence was $13.8 \%$, a slight increase over previous studies [1] (Table 1). The study also confirmed the association between diabetes, obesity and hypertension, and the importance of increased physical activity as a preventive measure. While obesity prevalence is almost $30 \%$ nationally, there is some concern that $6 \%$ of patients with Type II diabetes have not yet been diagnosed of their condition [1].

Lower estimates of diagnosed Type II prevalence have been reported, including 3.1\% in Aragon [6], 6.7\% in Catalonia [12], $4.6 \%$ in the Basque country [13], $4 \%$ in Asturias [14], 7.8\% in Murcia [15] and 8\% in Valencia [16]. The prevalence of diagnosed and undiagnosed Type II was 6.6\% in Andalusia [17], 6.1\% in Aragon [6], 7.8\% in Galicia [18], 10.3\% in Catalonia [12], 9\% in Asturias [14], 11.7\% en Balearic Islands [19], 12\% in Canary Islands [20], and 11\% in Murcia [15].

In Spain the National Health System (NHS) is a public health care insurance system with universal coverage of 47 million people. Administered by 17 regions, it is coordinated by the national government and fully financed by the general tax fund. Hospitals and primary health care centres are publicly owned, with some contracting out to private hospitals. Medical doctors are paid by salary. Primary care doctors act as gatekeepers. There are private health insurance companies and private practices, where specialists in particular play a complementary role, although some activities are totally private (dentistry). As a percentage of GDP, total health expenditure in Spain is $9.5 \%$ in the year 2009 (71\% public and

Table 1 Diabetes prevalence in Spain

\begin{tabular}{lcc}
\hline & $\begin{array}{c}\text { Prevalence \% } \\
(\geq \mathbf{1 8} \text { years) }\end{array}$ & $\begin{array}{c}\text { Prevalence Number } \\
(\geq \mathbf{1 8} \text { years })\end{array}$ \\
\hline Diabetes: Diagnosed & $\mathbf{7 . 8 \%}$ & $\mathbf{2 9 9 6 3 9 5}$ \\
\hline Diabetes: Undiagnosed & $\mathbf{6 . 0} \%$ & $\mathbf{2 3 0 4 9 1 9}$ \\
\hline Diabetes: Total & $\mathbf{1 3 . 8} \%$ & $\mathbf{5 3 0 1 3 1 4}$ \\
\hline Abnormal glucose tolerance & $\mathbf{9 . 2 \%}$ & $\mathbf{3 5 3 4 2 1 0}$ \\
\hline Impaired fasting glucose & $\mathbf{3 . 4 \%}$ & $\mathbf{1 3 0 6 1 2 1}$ \\
\hline Obesity: BMl> 30 & $\mathbf{2 8 . 2 \%}$ & $\mathbf{1 0 8 6 3 4 3 1}$ \\
\hline
\end{tabular}

Source: Soriguer F et al., 2012 [1].
$29 \%$ private). Public health expenditure represents $7.0 \%$ of GDP and per capita spending is $€ 1,604$ [21].

With regard to diabetes care, Spain offers a good health coverage system with well- developed care free at point of delivery. All diabetes expenses are fully covered by the NHS, with no out of pocket payments. Since 2007, there has been a national diabetes plan providing general guidelines to stimulate the implementation of regional programs for prevention, early diagnosis and efficient treatment, as well as research [22]. Some regions in turn have their own regional prevention plans.

The objectives of this paper are to identify and update diabetes costs, to present outcomes and quality of care, and to discuss challenges raised by diabetes for Spain's future. Evidence on direct costs and productivity losses of diabetes and related complications over the last decade will be presented as well as making expenditure projections for the Spanish NHS.

\section{Methods}

We performed systematic searches in electronic databases (Medline), grey literature, reports from national and international sources, including professional bodies and organizations, of published papers on the costs and outcomes of diabetes in Spain, period 2000-2010. It was conducted during September and December 2010. In undertaking the research, the following key words were used, both in English and Spanish language: "Spain + diabetes"; "Spain + diabetes + prevalence"; "Spain + diabetes + costs"; "Spain + diabetes + costs + complications"; "Spain + diabetes + outcomes"; "Spain + diabetes + guidelines". A number of studies were then selected on the basis of their correspondence with the costs, outcomes and organizations pertinent to Spain.

\section{Results and discussion}

The search generated 273 possible references. After reading abstracts or full articles, we identified four major studies [23-26] which investigated the costs of diabetes in Spain, including costs of complications.

The authors selected two national studies (bottom-up and town-down approaches) that had estimated the total cost of diabetes with a health service perspective [23,24]. A top-down regional study that had estimated the cost of diabetes with a broad perspective (societal costs) [25]. Finally, a fourth regional study that while used a bottom-up approach, for its large sample and broad perspective (societal costs) helped to supplement the information contained in the three previous studies [26].

\section{Cost of diabetes in Spain}

All recent Spanish studies on diabetes costs undertaken over the past few years were at national or regional levels. 
Two national studies [23,24] and two regional studies $[25,26]$, were identified which address direct diabetes costs using a similar approach, which made analysis possible. Therefore making them comparable (Table 2).

As part of the CODE 2 (Cost of Diabetes in EuropeType II) study, a national diabetes cost study was undertaken in Spain in 1998 to estimate Type II diabetes direct costs, and to differentiate care costs, costs of complications and other unrelated health costs [24]. This study used a bottom-up approach to costing and a health service perspective. The annual health cost was $€ 1,305 /$ patient of which $28.6 \%$ (€373) was for diabetes control, 30.5\% (€398) diabetes-related complications, and 40.9\% (€534) was unrelated. The mean cost of patients without complications was $€ 883$ compared to $€ 1,403$ with microvascular and $€ 2,022$ with macrovascular complications, and $€ 2,133$ with both types of complications [24].

Another national study estimated health care resources spent by Type I and Type II adult diabetic patients in Spain during the year 2002 [23]. This study used a topdown approach and a health service perspective. The estimated 2002 direct costs of diabetic people ranged from $€ 2.4-2.7$ billion depending on the prevalence estimate. Hospital costs were highest (€933 million), followed by non-insulin and non-hypoglycemic drugs (€777-932 million). Much lower were the insulin and oral hypoglycemic agents ( $€ 311$ million), primary care visits (€181-272 million), specialized visits ( $€ 127-145$ million), and disposable elements ( $€ 70-81$ million). Expenditures for all drugs and consumable goods ranged between $€ 1.2-1.3$ billion, representing $48-49 \%$ of total costs, $15 \%$ higher than hospital costs. The direct health care costs of diabetic patients were high (6.3-7.4\% of total NHS expenditure). The average annual cost was $€ 1,290-1,476 /$ patient, while nondiabetic was $€ 865 /$ patient [23].

In a smaller regional study, descriptive costing observations of 517 patients with Type II diabetes were collected [26]. This study used a bottom-up approach and they measured productivity losses (indirect costs) and a broad perspective (societal costs). Total annual health costs of $€ 4,278$ /patient were estimated (direct $€ 2,504$; indirect $€ 1,774$ ). Multiple regression analysis showed an independent association between total costs and obesity, male sex, number of diabetes-related hospitalizations, permanent disability, macrovascular complications, and having both micro- and macrovascular complications. Their findings confirm both the high economic cost of Type II diabetes and the direct relationship between costs and diabetes-related complications (obesity, permanent disability and micro-/macrovascular complications) [26].

An older regional cost of illness study evaluated the economic impact of direct health costs and the productivity losses (indirect costs) caused by diabetes in the Canary Islands in 1998 [25]. This study used a top-down approach and a broad perspective (societal costs). The total annual diabetes costs were $€ 39$ million, or $€ 758$ / diagnosed patient. Total annual diabetes direct costs were $€ 24$ million, approximately $2.13 \%$ of health expenditure; or the equivalent of $€ 470 /$ diagnosed patient. The largest

Table 2 Comparison of annual diabetes costs per patient in Spain

\begin{tabular}{|c|c|c|c|c|}
\hline & Mata et al. (CODE 2) & Oliva et al. & Ballesta et al. & Lopez Bastida et al. \\
\hline Publication year & 2002 & 2004 & 2006 & 2002 \\
\hline Reference year & 1998 & 2002 & 1999 & 1998 \\
\hline Type of study & $\begin{array}{l}\text { National, observational, } \\
\text { prevalence and bottom-up } \\
\text { approach. }\end{array}$ & $\begin{array}{l}\text { National, prevalence } \\
\text { and top-down approach. }\end{array}$ & $\begin{array}{l}\text { Regional, observational, } \\
\text { prevalence and bottom-up } \\
\text { approach. }\end{array}$ & $\begin{array}{l}\text { Regional, prevalence } \\
\text { and top-down approach. }\end{array}$ \\
\hline Type of costs & Direct health care costs & Direct health care costs & $\begin{array}{l}\text { Direct health care costs } \\
\text { and productivity losses } \\
\text { (human capital) }\end{array}$ & $\begin{array}{l}\text { Direct health care costs } \\
\text { and productivity losses } \\
\text { (human capital) }\end{array}$ \\
\hline Sources of resources used & Primary data. & Primary and secondary data. & Primary data. & Primary data. \\
\hline Diabetes Type & Type ॥ & Type | \& || & Type II & Type I \& || \\
\hline Age & $30-89$ years & $18+$ years & $14+$ years & $0-99$ years \\
\hline \multirow[t]{3}{*}{ Total costs } & $€ 1305$ & $€ 1290-1476$ & $€ 4278$ & $€ 758$ \\
\hline & & & Direct: $€ 2504$ & Direct: $€ 470$ \\
\hline & & & Productivity $€ 1774$ & Productivity: €288 \\
\hline Drug costs & $€ 554$ & $€ 636$ & $€ 851$ & $€ 179$ \\
\hline Hospitalization costs & $€ 417$ & $€ 512$ & $€ 1005$ & $€ 183$ \\
\hline$\%$ inpatient costs & $59.8 \%$ & $37 \%$ & $39 \%$ & $38 \%$ \\
\hline$\%$ outpatient costs & $18.5 \%$ & $17 \%$ & $28 \%$ & $23 \%$ \\
\hline$\%$ drug costs & $21.7 \%$ & $46 \%$ & $33 \%$ & $39 \%$ \\
\hline
\end{tabular}

Source: Data taken from the cost of illness studies [23-26]. 
portion of total diabetes costs (direct costs plus productivity losses) was direct costs at $62 \%$, while productivity losses came to $€ 15$ million [25].

This data (Table 2) was then used to create national diabetes expenditure projections. The first projection involves the total direct diabetes costs plus productivity losses. The direct health care cost per patient was taken from Oliva et al. [23] and the productivity losses from Lopez-Bastida et al. [25] and Ballesta et al. [26]. The costs were adjusted to 2009 taking into account annual inflation and population data from INE [27] and diabetes prevalence [1] (Table 3).

The second projection calculates the overall diabetesrelated complications, by applying per patient costs of diabetes-related complications onto the national prevalence. Annual micro- and macrovascular complication costs per patient $[23,24]$ were applied to diabetes prevalence [1] (Table 4).

\section{Allocation of resources and outcomes}

Type I diabetes patients are in general attended by endocrinologists, paediatric endocrinologists and diabetes nurses, frequently as hospital outpatients. Some tertiary hospitals have developed multidisciplinary diabetes units. Information about quality of care and final outcomes of Type I diabetes in Spain is scant, generally limited to single-centre results $[28,29]$.

Type II diabetes patients are mostly treated in a primary care setting, with varying participation of specialists, depending on available human resources as well as local or regional policies. Interventions aimed at improving the coordination and the delimitation of competences between health care levels are currently being promoted [30].

The Group for the Study of Diabetes in Primary Care of Health (GEDAPS) published their first edition of the "Guidelines for the Treatment of Type 2 Diabetes Mellitus in Primary Care" in 1993, with subsequent editions in 1995, 1998, 2000, 2004, and 2010 [31]. These guidelines are based on agreements made by diabetes health professionals, defining quality of care for Type II diabetic patients primarily based on the Saint Vincent Declaration which was adapted for primary care. Other less known Type II guidelines have been launched, including one endorsed by the Ministry of Health [32] and the Spanish Diabetes Society [33]. Only one set of Type I diabetes treatment guidelines are available and created by the Spanish Society of Endocrinology and Nutrition [34]. However, their dissemination has been rather limited.

Subsequent to GEDAPS guidelines, a GEDAPS Network (RedGEDAPS) was created by diabetologists nationally to promote quality improvements, in part via through the collection of intermediate and final complications outcomes (Table 5). Intermediate outcome indicators are glycosylated hemoglobin (HbA1c), total and high-density (HDL) cholesterol, blood pressure, BMI and urinary albumin. Prevalence of complications include diabetic retinopathy, cardiovascular disease (including stroke, MI), foot ulcerations and amputations, microalbuminuria, and hospital admissions with high blood sugar. These indicators are collected infrequently, to date 1996, 1998, 2000, 2002, and 2007. According to the RedGEDAPS audits, all indicators in Type II diabetes patients have progressively improved from 1996 to 2007 [35].

Diabetic retinopathy is a major cause of blindness in people under 60 years (20-30\%), while blindness prevalence amongst diabetes patients is $5-6 \%$, a risk 6 times higher than the general population. Almost all Type I diabetes patients have degeneration just after 14 years after diagnosis. Diabetic retinopathy is a major concern also in Type II patients with 33\% retinopathy, as well as 17\% with renal complications, $21 \%$ peripheral vascular disease, $10 \%$ cerebral vascular disease, 14\% coronary disease, and 40\% neuropathy. In Type II, at least half of patients have some type of complication at the time of diagnosis [36]. Despite improvements over time, diabetes-related complications continue to be significant (Table 5).

In a Spanish national cross-sectional multicenter study comparing 1,041 Type II patients enrolled in 29 primary care centers to 8,693 subjects from the general population, the HRQOL via the generic questionnaire (EQ-5D) was worse among diabetic subjects (mean EQ-5D index score of 0.71 vs 0.81 ). Diabetes patients with diabetesrelated complications, poor glycemic control and insulin treatment had worse HRQOL than diabetes patients without complications, adequate control or no insulin treatment [37].

Table 3 Direct and productivity losses of diabetes projections for 2009

\begin{tabular}{|c|c|c|c|c|c|}
\hline \multicolumn{2}{|c|}{ Spain $18+$ years } & Type II diabetes prevalence (\%) & Type II diabetes patients (n) & Annual Cost per patient $(€)$ & Total costs ( $€$ million) \\
\hline \multicolumn{6}{|c|}{ Direct costs } \\
\hline 2009 & 38553614 & $7.8 \%$ & 3007182 & 1660 & 5119.92 \\
\hline \multicolumn{6}{|c|}{ Productivity losses } \\
\hline 2009 & 38553614 & $7.8 \%$ & 3007182 & 916 & 2825.21 \\
\hline
\end{tabular}

Source: Authors' calculations based on INE population data [27], 2002 annual costs per patient [23] (inflated to 2009 using INE inflation rate), and diabetes prevalence [1]. 
Table 4 Cost of diabetes complications Type II in 2009

\begin{tabular}{|c|c|c|c|}
\hline & Total direct costs ( $€$ millions) & Direct cost per patient $(€)$ & Components of direct costs ( $€$ million, \%) \\
\hline \multirow[t]{3}{*}{ Macrovascular complications } & \multirow[t]{3}{*}{$€ 757.74$} & \multirow[t]{3}{*}{$€ 2776$} & Pharmaceuticals €263.69 (34.8\%) \\
\hline & & & Inpatient €334.16 (44.1\%) \\
\hline & & & Outpatient€159.88 (21.1\%) \\
\hline \multirow[t]{3}{*}{ Microvascular complications } & \multirow[t]{3}{*}{$€ 579.79$} & \multirow[t]{3}{*}{$€ 1928$} & Pharmaceuticals €241.19 (41.6\%) \\
\hline & & & Inpatient €189.59 (32.7\%) \\
\hline & & & Outpatient €149 (25.7\%) \\
\hline \multirow[t]{3}{*}{ Micro- and Macrovascular complications } & \multirow[t]{3}{*}{$€ 542.22$} & \multirow[t]{3}{*}{$€ 2930$} & Pharmaceuticals $€ 208.75$ (38.5\%) \\
\hline & & & Inpatient €217.97 (40.2\%) \\
\hline & & & Outpatient €115.49 (21.3\%) \\
\hline
\end{tabular}

Source: Authors' calculations based on diabetes prevalence [1], INE and adjusted diabetes-related complication costs updated from Mata et al., 2002 [24].

A similar study applying the HRQOL to 5,549 Canary Island citizens also found that subjects with diabetes presented a worse HRQOL than non-diabetic age- and sex-matched control subjects [38]. Average EQ-5D index score of diabetic people was 0.69 compared to 0.77 of the remaining sample (median EQ-5D index score was 0.83 among diabetic subjects vs. 0.88 among nondiabetic controls). Diabetes patients also had higher prevalence of moderate and severe problems in the five dimensions of EQ-5D (Mobility, Self-care, Usual activities, Pain/Discomfort, Depression/Anxiety) compared to the non-diabetic sample. These findings were concordant with a previous study of adults with diabetes, in which fair or poor health was two-fold higher in nondiabetic than in diabetic subjects, a finding unchanged over the 1993-2003 decade (71.2 to 70.5\%) [39].
A 2006 Catalonia health survey $(n=15,926)$ found a significant, moderately negative relationship between diabetes and HRQOL (via EQ=5D) [40]. Further subgroup analysis revealed diabetic subjects without vascular disease or associated risk factors had a similar HRQOL to the non-diabetic population. In contrast, diabetic individuals with vascular risk factors had significantly lower HRQOL than in non-diabetic subjects.

\section{Challenges and policy recommendations}

Major factors underpinning rising prevalence are an ageing population and rising obesity, the latter which has been steadily increasing primarily due to poor diet and low physical activity [41].

Specifically to Type II diabetes in Spain, the following conditions increase the risk of diabetes diagnosis [42].

Table 5 Type II Intermediate and final diabetes related complications outcome indicators (1996-2007)

\begin{tabular}{|c|c|c|c|c|c|c|}
\hline Intermediate & 1996 & 1998 & 2000 & 2002 & 2007 & $\begin{array}{l}\text { Difference } \\
(1996-2007)^{*}\end{array}$ \\
\hline $\mathrm{HbA} 1 \mathrm{c} \leq 7 \%$ & $43.0 \%$ & $49.2 \%$ & $56.1 \%$ & $53.4 \%$ & $59.0 \%$ & $16.0(15-17)$ \\
\hline $\mathrm{HbA} 1 \mathrm{c} \geq 10 \%$ & 10.1 & 6.4 & 5.3 & 4.5 & 4.6 & $5.5(4.9-6.1)$ \\
\hline HDL Cholesterol $>40 \mathrm{mg} / \mathrm{dl}$ or $>35 \mathrm{mg} / \mathrm{dl}$ if $>65$ years & 83.1 & 77.5 & 80.0 & 83.1 & 84.7 & $1.6(1.3-1.9)$ \\
\hline Total Cholesterol $<250 \mathrm{mg} / \mathrm{dl}$ & 75.0 & 75.4 & 83.1 & 78.0 & 77.5 & $2.5(2.1-2.9)$ \\
\hline BMI $<30$ & 62.2 & 59.3 & 62.0 & 56.8 & 48.9 & $13.3(12.4-14.2)$ \\
\hline Blood presure $<140 / 90 \mathrm{mmHg}$ & 59.1 & 53.6 & 59.6 & 63.1 & 65.1 & $6.0(5.3-6.7)$ \\
\hline Active smoking & 15.4 & 16.5 & 15.9 & 14.8 & 11.1 & $4.3(3.7-4.9)$ \\
\hline Final & 1996 & 1998 & 2000 & 2002 & 2007 & $\begin{array}{l}\text { Difference } \\
1996-2007\end{array}$ \\
\hline Diabetic retinopathy & $34.3 \%$ & $25.8 \%$ & $22.7 \%$ & $17.0 \%$ & $15.6 \%$ & $18.7(17.6-19.8)^{*}$ \\
\hline Diabetic foot ulcers & 5.7 & 4.1 & 6.6 & 2.5 & 3.1 & $2.6(2.2-3.0)^{*}$ \\
\hline Amputation: lower limb & 2.4 & 1.2 & 1.2 & 0.7 & 0.5 & $1.9(1.5-2.3)^{*}$ \\
\hline Microalbuminuria or proteinuria & 15.0 & 26.9 & 37.9 & 21.4 & 16.7 & $1.7(1.3-2.1)^{*}$ \\
\hline Cardiovascular: Stoke, MI & 21.4 & 18.8 & 19.0 & 18.1 & 14.5 & $6.9(6.2-7.6)^{*}$ \\
\hline $\begin{array}{l}\text { Hospital admission with blood glucose }>500 \mathrm{mg} / \mathrm{dl} \text { : amputation, } \\
\text { ketosis, hypoglycemia and other }\end{array}$ & 5.5 & 4.3 & 4.7 & 4.8 & 5.9 & $0.4(0.2-0.6)$ \\
\hline
\end{tabular}


Obesity is of significant concern in Spain, despite a climate favourable to exercise and a Mediterranean diet. Approximately one-third of adults are overweight (37\%) and $15.4 \%$ are obese. Even children are at risk for lifetime of chronic obesity-related conditions, with $9.4 \%$ of 2-17 year olds recorded as obese and $19.2 \%$ as overweight [43]. Approximately one-third of adults do not engage in any daily physical exercise, placing them at risk for developing excess body adipose [43].

Prevention, especially through promoting healthy life styles, must be further enforced in the policy agenda both at national and regional level. Primary prevention of diabetes is effective in decreasing the incidence of diabetes [22].

Scientific data support the efficacy of lifestyle measures used in Type II diabetes prevention, however, realities of program implementation in the general population pose some difficulties. This leads us to believe that socio-health, educational and fiscal policies are needed to implement lifestyle interventions in at-risk populations [44]. The Ministry of Health, in compliance with World Health Organization (WHO) guidance, advocates an integrated approach combining diabetes prevention, diagnosis and treatment [22].

The 2007 government strategy aims to coordinate tools within the NHS using the guiding principles of solidarity, equity and participation to achieve inequality reduction and the promotion of healthy lifestyles and a high quality of care [22]. The strategy was developed by a multidisciplinary team including scientific societies, patients and caregivers, the Ministries of Health of the Autonomous Communities (AC), and the cities of Ceuta and Melilla [22].

To configure this strategy, a survey by the Institutional Committee of the Diabetes Strategy at the NHS explored four main areas: health policy; organizational strategies; clinical strategies; and information systems and data records. Its 2006 results found diabetes was a priority area for health intervention in $94.3 \%$ of the Autonomous Communities (AC). Since then, only $31.6 \%$ have a diabetes action plan, with the exception of Navarre and Valencia community with plans in place since 1996. These plans are prepared and edited by the Ministries of Health $(\mathrm{MOH})$, usually led mainly by a $\mathrm{MOH}$ directorate or regional Health Service.

The AC play a significant role in diabetes policy, as $63.2 \%$ have diabetes advisory councils, composed of management, professional, scientific societies and patient associations. $68.5 \%$ of ACs have established standard coordination between primary and specialty care, mostly through agreed protocols, improvement committees, clinical sessions and training activities. In addition, $89.5 \%$ of ACs have a diabetes plan in primary care, and $84.2 \%$ have agreed protocols in place for monitoring DM in the different levels of care[22]. A further 57.5\% have defined specific action plans for preventing complications: there are programs for screening for diabetic retinopathy in $84.2 \%$ ACs, $84.2 \%$ for diabetic foot, and $89.5 \%$ for diabetic nephropathy [22].

There are differences in the distribution of endocrinology resources between ACs, although most (84.2\%) are located in hospitals and specialty centers. Some regions such as Catalonia, the Baleares and Melilla are centralized in hospitals alone. 52.6\% of ACs have day hospitals and single consultations for the continuing care of diabetic patients in health care[22].

In $80 \%$ of ACs, most of the actions that are carried out in relation to primary diabetes prevention are integrated into programs to prevent cardiovascular risk, obesity, education, health nutrition and healthy habits. Early detection activities are implemented in $84.2 \%$ of ACs, and $52.6 \%$ have some mechanism to detect and record the population at risk [22]. In $94.7 \%$ of ACs are diabetes education programs, carried out in $89.5 \%$ of the time by primary care teams and $68.4 \%$ by specialist care services. In $63.2 \%$ of $\mathrm{ACs}$, there are additional resources for diabetes education, from specialty care or primary care or both [22].

The Ministry of Health is encouraging the NAOS Strategy (Strategy for Nutrition, Physical Activity, and Obesity Prevention) to reduce obesity [45]. The PERSEUS Program (Pilot Program Reference School for Health and Exercise Obesity) included as one of the Quality Plan for the NHS, is aimed at preventing obesity in schools through interventions aimed at educators and students. In 2011 Spain had implemented a law requiring all schools to serve healthy foods and banned unhealthy ones from the premises.

The evaluation of diabetes patients within the health system is important in order to understand patient behavior and vision of their own health status, and explore their social context and environment variables to identify cultural, organizational and personnel influencing disease evolution. Patients with Type II diabetes, as experienced users of the health system, can be assessed "from below" the care services that treat them and, therefore, provide relevant and useful information to improve quality treatment and health management system [46].

Diabetes presents several challenges to the NHS and the wider Spanish society. The main challenge is to reduce the rising diabetes prevalence. Its evolution represents a real threat to the health of the population along with affordability of the health care system.

The multidimensional nature of the obesity problem will require a multi-faceted solution. The success of policies depends on a combination of measures that take into account cultural, economic and social aspects. As the increase in obesity rates are the result of cultural, 
social, economic and technological influences (i.e. sedentary jobs, lower prices of food rich in sugar and fat in comparison with fruit and vegetables, the high opportunity cost of cooking at home, the use of private cars instead of public transport, walking or cycling, and so on), it is difficult to identify cost-effective strategies.

Several limitations of this study must be recognized. First, diabetes prevalence is probably higher than the figures suggest due to significant numbers of undiagnosed diabetes cases. It also should be stressed that the present work does not consider non-health care direct costs or informal care costs faced by patients and society as a whole.

\section{Conclusions}

In this paper, we quantified direct medical costs and productivity losses of diabetic patients for 2009 in Spain, and found patients consumed $8 \%$ of total public health expenditures. We have estimated $€ 5.1$ billion for direct costs, with $€ 1.5$ billion for diabetes-related complications. Labour productivity losses amounted to $€ 2.8$ billion. The annual cost per diabetic patients averaged close to $€ 1,660$ for direct costs and $€ 916$ for productivity losses, with significant differences between patients with and without micro and macrovascular complications.

Diabetes, particularly including its complications, not only affects the health status of the individual, but also their ability to work during their productive life. Consequently, non-health social costs should be also taken into account when assessing the overall economic burden of diabetes. Since most of the Spanish studies relating to the cost of diabetes take into account only health care costs, it is necessary to include labour productivity losses and formal and informal care costs to obtain a better assessment.

The relative weight of different cost items is similar to the findings of other studies, with inpatient costs the primary consumer [47-49]. Many studies omit non-diabetes drug data, which is significant as polypharmacy is a frequent phenomenon among diabetic patients increasing with patient age, disease duration and the presence of complications. Most diabetic patients require diabetes drugs as well as treatment for co-morbidities and diabetes-related complications, particularly cardiovascular disease. Therefore, quality management of diabetes and chronic complications should be imperative.

Resources should not be allocated according to the costs of diseases but rather where interventions will benefit the most [50]. This study shows that diabetes costs illustrates the real dimension of health problems and reveals its true economic burden, quantifying health care and other resources that could be allocated elsewhere [51]. Working towards diabetes prevention as well as prevention of diabetes-related complications is a real goal, of which Spain has implemented a number of programmes to help towards this point.
Diabetes, alone and with its complications, affects individual health status as well as working abilities and productive life. Productivity losses should be accounted for in assessing the overall economic burden of diabetes. The only Spanish study accounting for productivity loss found it represented 36\% of overall expenditure [25]. Since most of the Spanish studies accounted only for direct costs, a more comprehensive assessment which includes productivity losses is necessary. Improved diabetes-related accounting within the NHS, along with regular collection and reporting of diabetes indicators and outcomes is needed.

The HRQOL in diabetics is not necessarily lower than in non-diabetics, provided that cardiovascular disease risk factors are under control and good glycaemic control is present. On the other hand, the presence of cardiovascular disease or its risk factors are associated with a significantly diminished quality of life for diabetic persons. The HRQOL should be included within a diabetes dataset including diabetes-related mortality, incidence and prevalence to aid in developing health policy and planning.

It is therefore essential for the Spanish health system to further boost prevention, both primary and secondary activities, as the main tool to reduce the incidence of Type II diabetes and diabetes-related complications. Improved data collection to monitor incidence, prevalence, expenditure and outcome indicators is needed to ascertain the position of diabetes in the Spanish health care system. Ironing out of regional inequalities is important not only for care access but also care planning and education provision. Ultimately, the key to reducing the impact of diabetes on society is in its prevention, and when this is not possible, then to at the very least, ensure good glycemic control to minimize costly diabetes-related complications.

\section{Abbreviations}

DM: Diabetes mellitus; CVD: Cardiovascular disease; NHS: National Health System; GDP: Gross domestic product; INE: Institute national of statistics; HRQOL: Health-related quality of life; EQ-5D: EuroQol EQ-5D.; WHO: World Health Organization; AC: Autonomous communities; $\mathrm{MOH}$ : Ministry of health.

\section{Competing interests}

The authors declare that they have no competing interests.

\section{Authors' contributions}

$J \mathrm{LB}$ conceived and designed the research, acquired the data, analyzed and interpreted the data, handled funding and supervision, drafted the manuscript and critically revised the manuscript for important intellectual content. MB acquired the data, analyzed and interpreted the data, critically revised the manuscript for important intellectual content. JOM conceived and designed the research, analyzed and interpreted the data and drafted the manuscript. WS conceived and designed the research, acquired the data, analyzed and interpreted the data, drafted the manuscript and critically revised the manuscript. All authors read and approved the final manuscript.

\section{Acknowledgement}

The work has been funded by an unrestricted educational grant by NovoNordisk. 


\section{Author details}

${ }^{1}$ University Castilla La Mancha, Avda Real Fábrica de Seda s/n, Talavera de la Reina, Toledo 45600, Spain. ${ }^{2}$ Red de Investigación en Servicios Sanitarios en Enfermedades Crónicas (REDISSEC), Spain. ${ }^{3}$ Section of Endocrinology and Nutrition, Hospital Universitario Insular, Avda. Marítima del Sur, s/nLas Palmas de Gran Canaria 35016, Spain. ${ }^{4}$ University Castilla La Mancha, Cobertizo de San Pedro Mártir s/nToledo 45071, Spain. ${ }^{5}$ LSE Health, London School of Economics, Houghton Street, London WC2A 2AE, UK.

Received: 13 October 2012 Accepted: 22 April 2013

Published: 1 May 2013

\section{References}

1. Soriguer F, Goday A, Bosch-Comas A, Bordiú E, Calle-Pascual A, Carmena R, Casamitjana R, Castaño L, Castell C, Catalá M, Delgado E, Franch J, Gaztambide S, Girbés J, Gomis R, Gutiérrez G, López-Alba A, Martínez-Larrad MT, Menéndez E, Mora-Peces I, Ortega E, Pascual-Manich G, Rojo-Martínez G, Serrano-Rios M, Valdés S, Vázquez JA, Vendrell J: Prevalence of diabetes mellitus and impaired glucose regulation in Spain: the Di@bet.es Study. Diabetologia 2012, 55:88-93.

2. Norlund A, Apelqvist J, Bitzen PO, Nyberg P, Schersten B: Cost of illness of adult diabetes mellitus underestimated if comorbidity is not considered. J Intern Med 2001, 250:57-65.

3. Cowie CC, Eberhardt MS: Diabetes 1996: Vital Statistics. Alexandria, VA: American Diabetes Association; 1996.

4. Sinclair AJ, Conroy SP, Bayer AJ: Impact of diabetes on physical function in older people. Diabetes Care 2008, 31(2):233-235.

5. Goday A: Epidemiología de la diabetes y sus complicaciones no coronarias. Rev Esp Cardiol 2002, 55:657-670.

6. Tamayo-Marco B, Faure-Nogueras E, Roche-Asensio MJ, Rubio-Calvo E, Sánchez-Oriz E, Salvador-Oliván JA: Prevalence of diabetes and impaired glucose tolerance in Aragon, Spain. Diabetes Care 1997, 20:534-536.

7. Goday A, Castell C, Tresserras R, Lloveras R: La diabetes mellitus tipo 1 en España. Estimación de la incidencia anual y su distribución por comunidades autónomas y provincias. Endocrinologia 1994, 41:301-304.

8. Goday A, Serrano-Ríos M, Castell C, Lloveras G, Gutiérrez R, Martull P, et al: Los estudios de incidencia de diabetes mellitus tipo 1 en España. Análisis comparativo y consenso de metodología estandarizada. Av Diabetol 1996, 12:24-28.

9. Giralt-Muiña P, Santillana-Ferrer L, Madrigal-Barchino D, Merlo-Garrido A, Toledo-De La Torre B, Anaya-Barea F: Incidencia en menores de 16 años y prevalencia de la diabetes mellitus tipo 1 en la provincia de Ciudad Real. Ann Esp Pediatr 2001, 55:213-218.

10. Carrillo-Domínguez A: Incidencia de la diabetes mellitus tipo 1 en las Islas Canarias (1995-1996). Rev Clin Esp 2000, 200:257-260.

11. Arteagoitia-Axpe JM, González-Carril F, Rodríguez-Murua JL, Piniés-Raposo JA: Diabetes mellitus, clasificación y epidemiología. In Diabetes mellitus 2: Impacto en la salud pública y estrategias de prevención. $8^{a}$ Monografía de la Sociedad Española de Epidemiología (SEE). Madrid: EMISA; 2008:11-38. http:// www.seepidemiologia.es/documents/dummy/Monograf\%C3\%ADa\%20SEE.pdf.

12. Castell C, Tresserras R, Serra J, Goday A, Lloveras G, Salleras L: Prevalence of diabetes in Catalonia (Spain): an oral glucose tolerance test-based population study. Diabetes Res Clin Pr 1999, 43:33-40.

13. Arteagoitia JM, Larrañaga MI, Rodriguez JL, Fernandez I, Piniés JA: Incidence, prevalence and coronary heart disease risk level in known Type II diabetes: a sentinel practice network study in the Basque Country, Spain. Diabetologia 2003, 46:899-909.

14. Botas P, Delgado E, Castaño G: Díaz de Greñu C, Prieto J, Díaz FJ: Prevalencia de diabetes mellitus e intolerancia a la glucosa en población entre 30 y 75 años en Asturias (España). Rev Clin Esp 2002, 202:421-427.

15. Valverde JC, Tormo MJ, Navarro C, Rodríguez-Barranco M, Marco R, Egea JM, Pérez-Flores D, Ortolá JB, González-Sicilia L, Tébar J, Sánchez-Pinilla M, Flores M, Cava J: Prevalence of diabetes in Murcia (Spain): a Mediterranean area characterized by obesity. Diabetes Res Clin Pr 2006, 71:202-209.

16. Catalá M, Girbés JA, Lluch I, Catalá MJ, Bataller A, Ampudia FJ: Estudio de prevalencia de diabetes en la comunidad Valenciana. Av Diabetol 2006, 22(l):25-26.

17. Aranda P, Villar J: Estudio epidemiológico andaluz sobre factores de riesgo vascular. Estudio Al-Andalus 90. Conserjería de Salud. Servicio Andaluz de Salud: Sevilla; 1993.
18. Muniz J, Hervada J, Juane R, Lopez Rodriguez I, Castro Beiras A: Prevalence of diabetes mellitus in the population aged 40-69 years in Galicia, northwest Spain. Diabetes Res Clin Pr 1995, 30:137-142.

19. Rigo F, Guillem J, Llobera J, Rodríguez T, Borrás I, Fuentespina E: Prevalencia de factores de riesgo cardiovascular en las Islas Baleares (estudio CORSAIB). Rev Esp Cardiol 2005, 58:1411-1419.

20. Cabrera-de León A, Rodríguez-Pérez MC, Del Castillo-Rodríguez JC, Brito-D íaz B, Pérez-Méndez LI, Muros De Fuentes M, Almeida-González D, BatistaMedina M, Aguirre-Jaime A: Estimación del riesgo coronario en la población de Canarias aplicando la ecuación de Framingham. Med Clin (Barc) 2006, 126:521-526.

21. García-Armesto S, Abadía-Taira MB, Durán A, Hernández-Quevedo C, BernalDelgado E: Spain: Health system review. Health Systems in Transition 2010, 12(4):1-295.

22. Consumo MdSy: Estrategia en diabetes del Sistema Nacional de Salud. Madrid; 2007:85. http://www.msps.es/organizacion/sns/planCalidadSNS/pdf/ excelencia/cuidadospaliativos-diabetes/DIABETES/ estrategia_diabetes_sistema_nacional_salud.pdf.

23. Oliva J, Lobo F, Molina B, Monereo S: Direct health care costs of diabetic patients in Spain. Diabetes Care 2004, 27(11):2616-2621.

24. Mata M, Antoñanzas F, Tafalla M, Sanz P: The cost of type 2 diabetes in Spain: the CODE-2 study. Gac Sanit 2002, 16(6):511-520.

25. López-Bastida J, Serrano-Aquilar P, Duque-Gonzalez B: Los costes socioeconómicos de la diabetes mellitus. Aten Primaria 2002, 29(3):145-150.

26. Ballesta M, Carral F, Olveira G, Girón JA, Aguilar M: Economic cost associated with type II diabetes in Spanish patients. Eur J Health Econ 2006, 7(4):270-275.

27. Instituto Nacional de Estadística: España en cifras 2011. Madrid; 2011:58. http:// www.ine.es/ss/Satellite?param1=PYSDetalleGratuitas\&c=|NEPublicacion C\&p= 1254735110672\&pagename=ProductosYServicios\%2FPYSLayout\&cid=1259924 $856416 \& \mathrm{~L}=0$.

28. Baena G, Carral F, Roca MM, Cayón M, Ortego J, Escobar L, Torres I, Gavilán I, Doménech I, García A, Coserria C, López C, Aguilar-Diosdado M: Can the metabolic control targets established for patients with type 1 diabetes be achieved in clinical practice? Endocrinol Nutr 2008, 55:442-447.

29. Pastor J, Bosch V, Fajardo MT, Goberna F, Vargas F: Diferencias de estado nutricional, control metabólico y tratamiento de la diabetes tipo 1 en dos décadas. An Pediatr(Barc) 2011, doi:10.1016/.anpedi.2011.04.011. in press.

30. Artola-Menéndez S, Rovira-Loscos A, Ricart W: Multidisciplinary coordination in the approach to type 2 diabetes mellitus. Med Clin(Barc) 2010, 135(2):27-32

31. Grupo de Estudio de la Diabetes en Atención Primaria de Salud: Guía para el tratamiento de la diabetes mellitus tipo 2 en atención primaria. 1.a ed. Barcelona: Haymarket; 1993:19.

32. Grupo de trabajo de la Guía de Práctica Clínica sobre Diabetes tipo 2: Guía de práctica clínica sobre diabetes tipo 2. Madrid: Plan Nacional para el SNS del MSC. Agencia de Evaluación de Tecnologías Sanitarias del País Vasco; 2008:181. http://www.guiasalud.es/egpc/diabetes/completa/index.html.

33. Menéndez-Torre $E$, Lafita-Tejedor J, Artola-Menéndez S, Millán-Núñez-Cortés J, Alonso-García A, Puig-Domingo M, García-Solans JR, Álvarez-Guisasola F, García-Alegría J, Mediavilla-Bravo J, Miranda-Fernández-Santos C, RomeroGonzález R: Recommendations for the pharmacologic treatment of hyperglycemia in type 2 diabetes. Av Diabetol 2010, 26(5):331-338.

34. Giménez $M$, Conget I: Algoritmo terapéutico de la diabetes mellitus tipo 1. Endocrinol Nutr 2006, 53(2):4-6.

35. Franch-Nadal J, Artola-Menéndez S, Díez-Espino J, Mata Cases M: The evolution of quality care indicators of patients with type 2 diabetes in the Spanish primary care (1996-2007). Med Clin (Barc) 2010, 135:600-607.

36. Morato-Griera J, Franch-Nadal J, Carrillo-Muñoz R, Via-Vidal M, Herrera-Ruiz A, Valerio-Sallent LL: Cronología de las complicaciones de la diabetes del adulto. El estudio del Raval Sur. An Med Intern 1995, 12(9):431-437.

37. Mata-Cases M, Roset-Gamisans M, Badia-Llach X, Antoñanzas-Villar F, RabelAlcázar J: Impacto de la diabetes mellitus tipo 2 en la calidad de vida de los pacientes tratados en las consultas de atención primaria en España. Aten Primaria 2003, 31(8):493-499.

38. Oliva-Moreno J, Lopez-Bastida J, Worbes-Cerezo M, Serrano-Aguilar P: Health related quality of life of Canary Island citizens. BMC Publ Health 2010, 10:675.

39. Jiménez-Garcia R, Jiménez-Trujillo I, Hernandez-Barrera V, Carrasco-Garrido P, Lopez A, Gil A: Ten-year trends in self-rated health among Spanish adults with diabetes, 1993-2003. Diabetes Care 2008, 31:90-92. 
40. Oliva J, Hidalgo A, Fernández-Bolaños A: Health-related quality of life in diabetic people with different vascular risks. Valencia, España: XXX Jornadas de Economía de la Salud; 2010.

41. Smyth S, Heron A: Diabetes and obesity: the twin epidemics. Nat Med 2006, 12(1):75-80.

42. Spanish Biomedical Research Centre in Diabetes and Associated Metabolic Disorders (CIBERDEM). http://www.ciberdem.org.

43. Ministerio de Sanidad y Política Social: Sistema Nacional de Salud de España 2010. Madrid: Instituto de Información Sanitaria; 2010. 2010. http://www.msps.es/organizacion/sns/docs/sns2010/Principal.pdf.

44. Gómez-Peralta F, Juanas-Fernández FE, Recio-Córdova JM: Estrategias para la prevención de la diabetes mellitus tipo 2. Presente y futuro. In Diabetes mellitus 2: Impacto en la salud pública y estrategias de prevención. $8^{a}$ Monografía de la Sociedad Española de Epidemiología. Madrid: EMISA; 2008:113-132.

45. Agencia Española de Seguridad Alimentaria: Estrategia NAOS: estrategia para la nutrición, actividad física y prevención de la obesidad. Madrid: Ministerio de Sanidad y Consumo; 2005. http://www.naos.aesan.mspsi.es/.

46. Herxheimer A, McPherson A, Miller R, Chapple A, Shepperd S, Ziebland S, Sanz E: DIPEx: Database of Individual Patients Experience of illness: a multimedia proposal to share experiences and information about illnesses between patients and health professionals. Aten Primaria 2003, 31(6):386-388.

47. MacLeod KM, Tooke JE: Direct and indirect costs of cardiovascular complications of type II diabetes. PharmacoEconomics 1995, 8(Suppl. 1):46-51.

48. O'Brien JA, Shomphe LA, Kavanagh PL, Raggio G, Caro J: Direct medical costs of complications resulting from Type II diabetes in the U.S. Diabetes Care 1998, 21:1122-1128.

49. Kangas T, Aro S, Koivisto VA, Salinto M, Laakso M, Reunanen A: Structure cost of health care of diabetic patients in Finland. Diabetes Care 1996, 19:494-497.

50. Donaldson C, Venkat-Narayan KM: The cost of diabetes: a useful statistic? (Letter). Diabetes Care 1998, 21:1370-1371.

51. Jonsson B: The economic impact of diabetes. Diabetes Care 1998, 21(Suppl. 3):C7-C10.

doi:10.1186/1744-8603-9-17

Cite this article as: Lopez-Bastida et al.: Costs, outcomes and challenges for diabetes care in Spain. Globalization and Health 2013 9:17.

\section{Submit your next manuscript to BioMed Central and take full advantage of:}

- Convenient online submission

- Thorough peer review

- No space constraints or color figure charges

- Immediate publication on acceptance

- Inclusion in PubMed, CAS, Scopus and Google Scholar

- Research which is freely available for redistribution 